\title{
Positive Organizational Behavior In The Workplace: A Cross-Cultural Perspective
}

Sunil J. Ramlall, Strategic HRM Consulting, LLC, USA

Ali Al-Kahtani, King Abdulaziz University, Saudi Arabia

Hind Damanhouri, King Abdulaziz University, Saudi Arabia

\begin{abstract}
Positive psychological principles and subsequently positive organizational behavior (POB) have become increasingly prevalent in the workplace in recent years. We have witnessed many struggles in the global economy where organizations across the world have experienced layoffs, lower productivity, lower employee morale, and generally struggling to be competitive. Given these negative environments, what can organizations do across the world to enhance the positive practices that will create benefits for all of the stakeholders through POB? We also identify gaps that exist in organizational practices and how positive organizational behavior can be integrated to build sustainable organizations.
\end{abstract}

Keywords: Positive Organizational Behavior; Positive Psychological Principles

\section{INTRODUCTION}

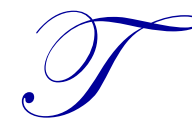

he impact on the current economic recession on the US workforce has been devastating. Consider the following indicators: The unemployment rate is about $8 \%$, and over the last year, it has risen by $2.3 \%$ points. Nearly 4.5 million jobs have been lost since the recession began around January 2008 (Froman, 2010). While there are no quick fixes to these complex and challenging problems, positive psychology, with its forward-looking orientation, suggests that the potential for a more hopeful, productive, and satisfying future can emerge for people who are struggling to find their way through these tough times, as well as for many others who are somewhat more secure, but find themselves coasting along without much joy and meaning in their day-today work lives (Froman, 2010). While in the US, much of this holds true, much of the world has experienced similar situations in the past few years.

Given the context of the workplace, hope has been found to support and sustain the capacity of workers to be resilient, to overcome adversity, and to bounce back in ways that strengthens their effectiveness (Youssef, 2007). It is in part through the continuous pursuit of developing and implementing strategies to maximize organizational effectiveness, organizations are studying and more frequently beginning to utilize theories and concepts from the Positive Organizational Scholarship (POS). POS provides opportunities for understanding the impact of organizational strategies on human behavior in the workplace and why some strategies and dynamic capabilities may be more generative than others (Cameron, Dutton, \& Quinn, 2003). This is especially relevant as positive psychology has flourished in the last seven years (Seligman, Steen, Park, \& Peterson, 2005). It may come as a surprise to learn that companies where the focus is on amplifying positive attributes such as loyalty, resilience, trustworthiness, humility, and compassion--rather than combating the negatives--perform better, financially and otherwise (Fryer, 2004).

Following the lead of positive psychology, that is, "what is good about life is as genuine as what is bad and therefore deserves equal attention" (Peterson, 2006, p. 4), is the recently emerging field of positive organizational behavior, or simply POB. Just as positive psychology does not claim to have discovered the importance of positivity to people, $\mathrm{POB}$ also recognizes that over the years there have been many positive constructs in organizational research such as positive affectivity (PA), positive reinforcement, procedural justice, job satisfaction and commitment, pro-social and organizational citizenship behaviors, core self-evaluations, and many others. 
Instead, positive psychology, and now its application to the workplace as POB, simply attempts to give a renewed emphasis (not a revolution or paradigm shift) to the importance of a positive approach.

Although this recent positive emphasis in organizational behavior is based on traditional theory-building processes and research methodologies, there is an attempt to study new, or at least relatively unique to the workplace, positive psychological resource capacities. This research would study the use, value, and impact of these positive constructs in Saudi Arabia and measure the impact on individual performance

\section{PURPOSE OF WORK AND THE RELATIONSHIP TO SATISFACTION, COMMITMENT, AND PERFORMANCE}

The focus on the wellness end of the continuum is the foundation behind positive psychology, POS, and POB - all of which are methodological approaches based on the premise that modifying our perspectives and understandings of ourselves, others, and the world around us will promote growth and development in ways that lead to higher levels of actualization and increased performance in our work settings (Zander, 2002). Another premise linking positive psychology and the positive organizational approaches of POS and POB is the explicit focus on developing and working with the human element of organizations. Rousseau and Ling (2007) noted that resources, in the understanding of positive organizational relationships, can be directly traced to psychodynamics and the positive psychology literature.

A study by Kuchinke et al. (2011) found support for the universal valuation of work and family as major life domains and the relative importance of leisure, religion, and community involvement. Work centrality was related in differentiated ways to performance orientation, assertiveness, and humane orientation indices. Extrinsic and intrinsic work goals differed and were related to country clustering.

So then, how do you frame work in relation to the rest of life? In a Newsweek article, Seligman (2002) describes the manner in which scholars distinguish three kinds of "work orientation": a job, a career, and a calling. You do a job for the paycheck at the end of the week, and when the wage stops, you quit. A career entails a deeper personal investment in work. A calling is a passionate commitment to work for its own sake.

Seligman also explained that part of what turns a job into a calling is the state known as flow. Csikszentmihalyi (1997) defines flow as complete absorption in an activity whose challenges mesh perfectly with your abilities and explained that flow is not the pleasure you derive from a warm shower or a cold beer but the loss of self-consciousness you experience while engrossed in a task that calls on your strengths. People who experience it are not only happier but more productive.

Furthermore, Wrzesniewski (2003) found that the way people see their work is highly predictive of their own individual thriving, and has positive implications for groups and organizations where they belong. Given one's personal self-defined purpose of life, the nature of one's work becomes a central component of fulfilling a person's purpose of life. The premise is therefore set forth that the stronger the linkage between the work one performs and the congruence to one's purpose of life, higher performance output can be expected. While many of us accept jobs and quickly become frustrated, it may simply be incongruence between the nature of the responsibility and our personal values, needs, and sources of our pleasure.

An organization's success depends on employees' creativity, innovation, and commitment. As employees, we can significantly enhance our organization's performance by inspiring the soul, creativity and maximizing the potential of the workforce. POB enables organizations to undertake a more complete view of the individual employee enabling a better understanding of the workforce and a strategic means to influence behaviors.

Of all human activities, creativity comes closest to providing the fulfillment we all hope to get in our lives (Csikszentmihalyi, 1996). Creativity is a central source of meaning in our lives. Most of the things that are interesting, important, and human are the result of creativity. 
Furthermore, POB enables employees to understand the work they do, their colleagues, those who they work for and those who work for them. The value of such knowledge is that stronger team efforts would prevail given a higher level of appreciation for others and the inter-subjectivity that exists within the workforce. Given the significant number of hours, employees spend at work, why shouldn't work be a place where one is able to achieve a sense of fulfillment about life and further complements one's life's purpose?

Historically, most of the research has focused on the negative side of work. As stated by Cameron et al., there is much more focus on negative images of violence in the workplace, organizational failings, and corporate leaders going to prison. Moreover, organizational behavior continues to look on the dark side and dwell on the concepts of uncertainty management, organized anarchy, disorganization theory, loosely coupled systems, and chaos theory. POB sets forth to understand the positive aspects of work and the impact on employee and firm performance.

\section{WORK AS A SIGNIFICANT SOURCE OF HAPPINESS}

The earliest writings of philosophers pondered the virtues of positive thinking and the pursuit of happiness (Judge \& Ilies, 2004). For example, Aristotle argued that happiness is the highest good humans can achieve and that the use of reason and rationality was essential to its achievement. More recently, the Dalai Lama wrote that the very purpose of our life is to seek happiness (Dalai-Lama \& Cutler, 1998).

In today's society, many will argue that work is the source of their stress, inability to spend adequate time with family, volunteering in community activities, and being unable to further their education. Seligman (2002) teaches that happiness can be cultivated by identifying and using the strengths people already possess. These strengths include kindness, originality, humor, optimism, and generosity.

Judge \& Ilies, (2004), Seligman et al. (2005), and Wright \& Cropanzano (2004) all have made outstanding cases that positiveness, as reflected in positive individual traits and positive feelings experienced at work, is important for employees' happiness and well-being. Furthermore, the benefits for the organizations are highly significant. Since positiveness, happiness, and organizational outcomes are interrelated, the leading scholars on POB believe that positiveness and happiness should preoccupy not only philosophers and psychologists, but also managers and organizational leaders.

Wright and Cropanzano (2004) reported that happiness is a valuable tool for maximizing both personal betterment and employee job performance. Applied research's interest in employee happiness has long centered on the happy/productive worker thesis. However, the results have sometimes proved disappointing. A study conducted by Gavin \& Mason (2004) reported on the importance of happiness at work stating that every society has jobs that must be done in order for it to survive and to improve its members' lives. Consequently, work is an important source of peoples' well-being.

The study also reported that many American workers are spending much more time at work. Recent surveys have shown that over 25 million of the 130.5 million workers in America work 49 or more hours a week. Over 10 million spend 60 hours or more at work.

The search for excellence and all-round happiness has been the important objective of mankind since ages. Happiness can be attained either through self-contentment or through fulfillment of desires. When someone tries to attain happiness through the latter, creation and distribution of goods and services occupy the central stage which is translated into business (Sharma \& Talwar, 2004).

Over the years, many organizational leaders and managers have argued the relationship between happy and satisfied employees with productive employees. Wright and Cropanzano (2003) have shown through their research that positive work behaviors have statistically significant relations to employee performance. Furthermore, the concept and practice of $\mathrm{POB}$ enables a good life for individuals and organizations and enables employees to be at their best at work. Seligman (2002) identified subjective experiences as one of the three related topics. These experiences may include happiness, pleasure, gratification, fulfillment, and well-being. 


\section{POSITIVE ORGANIZATIONAL CULTURES AND THE IMPACT ON EMPLOYEE SATISFACTION AND PERFORMANCE}

In recent years, strategy scholars have begun to look beyond industrial economics-based notions of strategy to try to better understand how organizations sustain their competitive advantage (Amit \& Schoemaker, 1993; Barney, 1991; Mahoney \& Pandian, 1992; Wernerfelt, 1995). Based on numerous studies, organizational culture is a core component of the sources that foster competitive advantages in organizations (Pfeffer, 1998; Pringle \& Kroll, 1997). Prevailing research claims that strong corporate cultures improve firm performance by facilitating internal behavioral consistency (Sørensen, 2002).

Building a positive organizational culture would be based around the concept of enhancing satisfaction, motivation, and productivity in the workplace (Martin, 2004). Wiegand and Geller (2004) also point to a number of strategies to enhance individuals' success orientation and conclude their discussion with the actively caring model which appears to be a useful means of representing pivotal facets of a positive and supportive workplace climate.

Important environmental features in work settings have sometimes been brought together under the general heading of 'climate', usually measured through individuals' perceptions of their organization's policies and practices (e.g., Ashkenasy, Wilderom, \& Peterson, 2000; Schneider, 1990).

Central to building and sustaining an organization's culture is the leadership of the organization. Typically, an organization's culture is a reflection of the leaders of an organization. POB and authentic leadership are the important characteristics of humans in the growth of an organization (Gardner \& Schermerhorn, 2004).

POS takes a rigorous look at the more widespread social constructs, values, and processes that make organizations great. And because it measures results, positive organizational scholarship goes beyond platitudinous talk about the virtues of being good. Southwest Airlines; for example, isn't the envy of the airline industry merely because it has a competitive cost structure or because founder Herb Kelleher, now retired, was a cool guy. The company is successful, these researchers contend, because it carefully protects and nurtures its employees (Fryer, 2004).

In searching for other examples of positive leaders who have helped to build positive organizational cultures, Bill George is a good place to start. During his twelve years of leadership at Medtronic Inc., the firm's market capitalization rose from $\$ 1.1$ billion to $\$ 60$ billion. George attributes Medtronic's success to the creation of a transparent organizational culture that reflects a commitment to integrity, customer satisfaction, employee development, and responsible leadership (Gardner \& Schermerhorn Jr., 2004).

\section{DISCUSSION AND CONCLUSION}

Although the importance of positive feelings has been recognized through the years in the academic OB and popular literature, both management scholars and practitioners have arguably too often taken a negative perspective - trying to fix what is wrong with managers and employees and concentrating on weaknesses (Luthans \& Church, 2002).

Positive psychology and POB are becoming established as a reputable sub-discipline in psychology and OB despite having neglected the role of positive reinforcement in enhancing quality of life (Wiegand \& Geller, 2004). While positive organizational cannot cure all of the challenges that exist in organizations globally, there are surely strategies in which leaders can extrapolate from the literature including discussions in this paper, to foster healthier and more productive organizations. Rather than focusing almost exclusively on expense optimization, layoffs, labor cost reductions, and reducing benefits, hopefully we are all able to integrate positive practices and increase resilience, appreciative inquiry, empowerment, gratitude, psychological capital, work engagement, supervisor and organizational support, positive teamwork and co-worker relations, and positive leadership.

Positive organizational scholarship is inspiring researchers to look at work in a whole new light--and they are finding that employee happiness really does pay. It's beginning to look as if a positive workplace atmosphere is 
worth developing, and not merely for its own sake; it may be the foundation of true organizational success (Fryer, 2004). As with others, this holds true for us as authors of this article. We are often focused on the negatives of life and all the workplace offers but creating a more positive environment can lead to immense positive energy, consequences, and outcomes. So by bringing awareness of these positive strategies and outcomes, hopefully managers and other leaders with organizations can utilize these frameworks and strategies to create a more positive workplace and better organizational outcomes.

\section{AUTHOR INFORMATION}

Dr. Sunil Ramlall is President of Strategic HRM Consulting, LLC. He is widely published in various business journals focusing on positive organizational behavior, strategic HRM, and employee training and development. His Ph.D. is from the University of Minnesota. E-mail: sramlall001@ gmail.com (Corresponding author)

Dr. Ali Al-Kahtani is an Associate Professor at King Abdulaziz University. His Ph.D. is from Cardiff University in the UK and has been teaching at KAU since 1991. He is a member at several management associations and publishes regularly in various business journals.

Dr. Hind Damanhouri joined the Faculty of Economics and Administration at King Abdulaziz University in 1976. Her research focus is on organizational behavior, work-related stress, and human resource management in the Saudi private sector. Her research has appeared in journals such as the Academy of Business Journal. Her PhD in Human Resource Management is from the University of Portsmouth - United Kingdom.

\section{REFERENCES}

1. Amit, R., \& Schoemaker, P. (1993). Strategic assets and organizational rent. Strategic Management Journal, 14(1), 33-46.

2. Barney, J. (1991). Firm resources and sustained competitive advantage. Journal of Management, 17(1), 99120.

3. Cameron, K., Dutton, J., \& Quinn, R. (2003). Foundations of positive organizational scholarship. In R. Quinn (Ed.), Positive organizational scholarship - Foundations of a new discipline (pp. 3-14). San Francisco, CA: Berrett-Koehler Publishers, Inc.

4. $\quad$ Csikszentmihalyi, M. (1996). The creative personality. Psychology Today, 29(4), 36.

5. $\quad$ Csikszentmihalyi, M. (1997). Finding flow. Psychology Today, 30(4), 46.

6. Dalai-Lama, \& Cutler, H. (1998). The art of happiness. New York: Riverhead Books.

7. Froman, L. (2010). Positive psychology in the workplace. Journal of Adult Development, 17(2), 59-69.

8. $\quad$ Fryer, B. (2004). 11| Accentuate the positive. Harvard Business Review, 82(2), 22-23.

9. Gardner, W., \& Schermerhorn, J. R., Jr. (2004). Unleashing individual potential: performance gains through positive organizational behavior and authentic leadership. Organizational Dynamics, 33(3), 270282.

10. Gardner, W., \& Schermerhorn Jr., J. (2004). Unleashing individual potential performance gains through positive organizational behavior and authentic leadership. Organizational Dynamics, 33(3), 270-281.

11. Gavin, J., \& Mason, R. (2004). The virtuous organization: The value of happiness in the workplace. Organizational Dynamics, 33(4), 379-392.

12. Judge, T., \& Ilies, R. (2004). Is positiveness in organizations always desirable? Academy of Management Executive, 18(4), 151-155.

13. Kuchinke, K. P., Ardichvili, A., Borchert, M., Cornachione, E. B., Cseh, M., Kang, H.-S. T., et al. (2011). Work meaning among mid-level professional employees: A study of the importance of work centrality and extrinsic and intrinsic work goals in eight countries. Asia Pacific Journal of Human Resources, 49(3), 264284.

14. Luthans, F., \& Church, A. H. (2002). Positive organizational behavior: Developing and managing psychological strengths. Academy of Management Executive, 16(1), 57-72.

15. Mahoney, J., \& Pandian, J. (1992). The resource-based view within the conversation of strategic management. Strategic Management Journal, 13(1), 363-380. 
16. Martin, A. J. (2004). The role of positive psychology in enhancing satisfaction, motivation, and productivity in the workplace. Journal of Organizational Behavior Management, 24(1/2), 113-133.

17. Pfeffer, J. (1998). The human equation: Building profits by putting people first. Boston, MA: Harvard Business Review Press.

18. Pringle, C., \& Kroll, M. (1997). Why Trafalgar was won before it was fought: Lessons from resource-based theory. Academy of Management Executive, 11(4), 73-89.

19. Rousseau, D. M., \& Ling, K. (2007). Commentary: Following the resources in positive organizational relationships. In J. E. Dutton \& B. R. Ragins (Eds.), Exploring positive relationships at work: Building a theoretical and research foundation (pp. 373-384).

20. Seligman. (2002). How to see the glass half full. Newsweek, 140, 48.

21. Seligman, Steen, T. A., Park, N., \& Peterson, C. (2005). Positive psychology progress. American Psychologist, 60(5), 410-421.

22. Seligman, M. (2002). Authentic happiness: Using the new positive psychology to realize your potential for lasting fulfillment. New York: Free Press.

23. Sharma, A., \& Talwar, B. (2004). Business excellence enshrined in Vedic (Hindu) philosophy. Singapore Management Review, 26(1), 1-19.

24. Sørensen, J. (2002). The strength of corporate culture and the reliability of firm performance. Administrative Science Quarterly, 47(1), 70-92.

25. Wernerfelt, B. (1995). The resource-based view of the firm: Ten years after. Strategic Management Journal, 16, 171-174.

26. Wiegand, D. M., \& Geller, E. S. (2004). Connecting positive psychology and organizational behavior management: Achievement motivation and the power of positive reinforcement. Journal of Organizational Behavior Management, 24(1/2), 3-25.

27. Wright, T. (2003). Positive organizational behavior: An idea whose time has truly come.

28. Wright, T., \& Cropanzano, R. (2004). The role of psychological well-being in job performance: A fresh look at an age-old quest. Organizational Dynamics, 33(4), 338-351.

29. Wrzesniewski, A. (2003). Finding positive meaning in work. In R. Quinn (Ed.), Positive organizational scholarship - foundations of new discipline. San Francisco: Berrett-Koehler Publishers, Inc.

30. Youssef, C. M., \& Luthans, F. (2007). Positive organizational behavior in the workplace: The impact of hope, optimism, and resilience. Journal of Management, 33, 774-800.

31. Zander, R. S., \& Zander, B. (2002). The art of possibility. New York: Penguin. 